\title{
Bipolar Endometrial Resection (BER) Versus Non Descent Vaginal Hysterectomy (NDVH) For Leiomyoma Induced Heavy Menstrual Bleeding
}

Ashraf Nassif Mahmoud Elmantwe Lecturer of Obstetrics and Gynecology Department, Benha University Hospital, Benha University Egypt
Corresponding author :

Ashraf Nassif Mahmoud

Elmantwe

Department of Obstetrics and

Gynecology,

Benha University Hospital, Banha University

ashrafnassif2002@yahoo.com.

$+01001801244$

\begin{abstract}
$\underline{\text { Abstract }}$
Aim: To compare the efficacy of Bipolar endometrial resection (BER) with that of non descent vaginal hysterectomy (NDVH) in control of heavy menstrual bleeding (HMB) induced by leiomyoma.
\end{abstract}

Patients \& Methods: An open label randomized controlled trial was conducted between February 2013 and October 2014 in Benha University Hospital, Benha, Egypt. Eligible women with HMB (Aged $\geq 40$ years and $\leq 50$ years, uterine size $\leq 12$ weeks of pregnancy, leiomyoma $\leq 3 \mathrm{~cm}$, uterocervical $\leq 12 \mathrm{~cm}$ ) were randomly assigned $(1: 1)$ to undergo BER or NDVH by closed envelopes method. The primary outcome was the number of women in the BER group with HMB 6 months after surgery. Analyses were by intention to treat.

Results: Each group contained 20 women. No women in BER had HMB at 6 months. Twelve women were amenorrheic and eight women were hypomenorrheic by 6 months.

Conclusion: BER can replace NDVH in some perimenopausal women to control HMB induced by small leiomyomas.

Keywords: BER, NDVH, EA, HMB.

\section{Introduction}

Heavy menstrual bleeding (HMB) accounts for 30\% of all gynecologic complaints, and it is a direct cause of significant health related burden for women, their families and society as a whole ${ }^{(1)}$. Leiomyomas found in $20-77 \%$ of premenoposual women and is one of main cause of $\mathrm{HMB}^{(2)}$. Leiomyomas induce HMB by increasing the endometrial surface area as well as vascularity and blood flow to the uterus ${ }^{(3)}$.

Surgical treatment of HMB often follows failed or ineffective medical therapy. Hysterectomy has traditionally been regarded as the definitive surgical treatment for HMB especially if theiris associated leiomyomas. However in spite of $100 \%$ success rate in inducing amenorrhea and high level of satisfaction, it is a major surgical procedure with significant physical and emotional complications and social and economic costs ${ }^{(4)}$. Vaginal hysterectomy is considered the gold standard route for hysterectomy in treatment of the begin condition, but still associated with the risk of any major surgery ${ }^{(5)}$.

Endometrial ablation (EA) is effective minimally invasive surgical procedure that has became a well established alternative to medical treatment or hysterectomy to treat HMB in select cases ${ }^{(6)}$. However EA is underutilized as most of non-resectoscopic endometrial ablation (NREA) are not available and its disposable is so costly, moreover due to high risks associated with monopolar resectoscopic endometrial resection /ablation (MREA) and high cost of standard bipolar hysteroscopy and special skill 
needed for MREA. Recently a modifying units that converts monopolar hysteroscopy to bipolar at a lower cost were available.

The current study hypothesized that the endometrial resection in perimenopasual women with $\mathrm{HMB}$ induced by leiomyoma will remove the basal endometrial layer as well as any intracavitery leiomyomas resulting in improvement in HMB until natural menopause, after which leiomyomas are known to regress.

This trial was conducted to compare outcomes of Hysterectomy, by minimal access route which is vaginal (NDVH) and endometrial ablation by low cost less risky Bipolar endometrial resection (BER) for treatment of HMB induced by uterine leiomyomas as regards control of $\mathrm{HMB}$ complaint, improvement of hemoglobin, operative events and quality of life measures.

\section{Patients and Methods}

This trial was an open label, randomized controlled trial, done at Department of Obstetrics and Gynecology, Benha University Hospital, Benha, Egypt, between February 2013 and October 2014. Women enrolled in this trial consecutively and were eligible to be included if they were older than 40 years and less than 50 years, had no desire for future childbearing, complaining of $\mathrm{HMB}$ with pictorial blood loss assessment chart (PBAC) score $>100$ with failed medical treatment, had uterine size up to 12 week of pregnancy with leiomyomas of $\leq$ $3 \mathrm{~cm}$ and uterocervical length of $\leq 12 \mathrm{~m}$.

Women didn't included if they were with acute pelvic inflammatory disease or gynecologic precancerous lesions as cervical intraepithelial neoplasia, atypical endometrial hyperplasia or gynecologic cancers or adenomyosis or suspected pelvic adhesion or suspected pelvic endometriosis. Ethical approval for the trial were obtained from faculty ethics committee, also all women whom participated in this trial provided written informed consent.

All participants were subjected to a detailed clinical history, a completed physical examination including PBAC scoring. All preoperative investigations were undertaken, including $\mathrm{CBC}$, cervical smear, transvaginal ultrasonography, endometrial sampling.

The uterine fibroid symptom and quality of life (UFSQOL $)^{(7,8)}$ questionnaire was used to assess the quality of life before and after the procedures. The UFS-QOL score is two parts, the symptom severity score (SSS) and the health related quality of life (HR - QOL) score. SSS includes questions related to severity of symptoms and HR-QOL score includes questions pertaining to concern, energy, activities, control, self consciousness and sexual function. The SSS was subjected to formula to get uterine fibroid symptom transformed score (UFS-TS) where high score values are indicative of greater symptom severity and lower scores will indicate minimal symptoms severity (High scores $=$ bad). The HR-QOL score was subjected to formula to get quality of life health related transformed score (HR-TS), where higher scores will be indicative of better health related quality of life.

Both BER and NDVH were done under spinal anesthesia with sedation in cycle postmenstrual phase in NDVH group or after 4-6 weeks of oral cidolut nor $5 \mathrm{mg}$ table every 6 hour (cide - Egypt) in BER group to induce endometrial thinning. NDVH was performed according to stander clamping suturing technique. BER was performed by $26 \mathrm{f}$ resectoscope of KARL STORZ to which a bipolar loop and converter of (LAMIDEY NOURY MEDICAL, working element and bipolar electrode for STORZ resector, $\mathrm{CH} 26$ double flow) V12PR10G-V12PRIG, Buisson, France), was applied and connected to (LAMIDEY NOURY MEDICAL, electrosurgical generator, Prima 730, Buisson, France) working on gynecologic large loop resection module at ( 160 w cutting, 80 w coagulation). Saline $0.9 \%$ were used with hysteromat of KORL STORZ to distend the uterine cavity. The fluid deficit were considered to be, the difference between used bottles and that collected in suction container with that suspected to be lost. A deficit up to $2500 \mathrm{ml} \mathrm{NaCl} 0.9 \%$ was considered the limit after which the procedure was stopped. The ball was used to coagulate the uterine cornu and fundus while the loop was use to resect the whole endometrium to cervicouterine junction.

Intraoperative variables including blood loss, duration of surgery, need for blood transfusion, complications and technical difficulty were compared in both groups. Technical difficulty graded as easy, difficult, very difficult. Postoperative pain severity was evaluated by visual analogue scale (VAS) score at 3, 12, 24 hours Both narcotic and non steroidal anti-inflammatory drug (NSAID) were used to control postoperative pain and total amount of inpatient use of analgesic were assessed in both groups. Duration of hospital stay and early and late postoperative complication. including infection, fever, endometritis, pneumonia, thromboembolism, hematoma, cellulites and abscess formation were noted and compared in both groups The frequency of adverse events such as hematometra and postablation tubal sterilization syndrome was noted in women who underwent BER.

Follow up was undertaken at 1, 3, 6, 12 months after 
surgery to assess menstrual blood loss (PBAC score) in women in BER group and hemoglobin levels in both groups. Improvement of symptoms and UFS -QOL scores (SSS and HR-QOL scores) were assessed in all participants at six month postoperative follow up. Women in BER group were also assessed at 12 and 24 month postoperative for recurrence of HMB.

Participants were randomly allocated into two groups (BER and $\mathrm{NDVH}$ ) in a $1: 1$ ratio using closed envelopes method. Participants, data collectors were not blind to group assignment.

A sample size of 40 was considered adequate assuming that $40 \%$ of women in the NDVH group and $13 \%$ in BER group would experience adverse events (minor and major) and a reduction in PBAC of 345 in women undergoing BER, with $80 \%$ power at $5 \%$ level of significance $^{(9,10)}$.

The primary outcome measure was the number of women with HMB in BER group 6 months after surgery. Secondary outcome measures were improvement in hemoglobin levels, intraoperative, postoperative events, and UFS-QOL scores in both groups.

Statistical analyses were by intention to treat and were performed by statistical calculator and medcalc easy - to - use statistical software for windows desktop (www.medcalc.org) 2016 (Medcalc, software bvba). Categorical variable are presented in terms of frequencies and percents, while continuous variables are presented in terms of means, stander deviations and ranges. Student's t test for independent samples and paired sample were used to compare continuous variables as baseline demographic and clinical criteria, changes in hemoglobin, changes in UFS-QOL score, visual analogue scale scoring, amount of analgesia operative time and blood loss as appropriate. Fisher's exact test was use to compare categorical variables as symptoms resolution and technical difficulty. P values and mean difference with $95 \%$ confidence intervals (CIs) were used to determine significance, $\mathrm{P}<0.05$ was considered statistically significant.

\section{$\underline{\text { Results }}$}

In this trial, 40 women were randomized to either BER or NDVH (Fig. 1). All patients were followed for at least 12 Months postoperative and all women in BER group followed for 24 months after surgery.

Baseline characteristics of women in both groups were not statistically different, as presented in table (1).

In BER group as regards the primary outcome no women had HMB at 6months postoperatively. Twelve
$(60 \%)$ patients became amenorrhic after 1 Month and Continued up to 6 Months. Four $(20 \%)$ was hypomenorrheic (PBAC score $<80$ ) at one month and continued up to 6 months. Four $(20 \%)$ patients was with PBAC score of $110-160$ at one month but became hypomenorrheic at 6 month follow up (PBAC score $<80$ ). At 12 months follow up in BER group, $3(15 \%)$ women had recurrence of $\mathrm{HMB}$, whom choiced underwent NDVH, while $12(60 \%)$ remained amenorrheic and $5(25 \%)$ remained hypomenorrheic. At 24 months, of the 17 patients in BER group who had not undergone NDVH, 12 (71\%) remained amenorrheic and 5(24\%) had hypomenorrhea.

Following BER and NDVH, statistically significant increase in hemoglobin values were noted during study period, in the BER group mean hemoglobin was $10.12 \mathrm{mg} / \mathrm{dl}( \pm 1.31)$ preoperatively, raised to $12.72( \pm$ $0.91) \mathrm{gm} / \mathrm{dl}$ at 12 month postoperatively $(\mathrm{P}<0.0001)$ while in NDVH, it was raised from $9.98( \pm 1.12) \mathrm{gm} /$ $\mathrm{dl}$ to $12.52( \pm 0.81) \mathrm{gm} / \mathrm{dl}$ at the same time period $(\mathrm{P}$ $<0.0001)$. While there was no significant difference between both groups regards the rise in the hemoglobin $(\mathrm{P}=0.85)($ Table 3$)$.

Operative time was significantly shorter in BER group than in the NDVH group $(\mathrm{P}<0.0001)$ table (4). Blood loss was significantly lower in BER group (P $<0.0001$ ) (table 4). The number of operations assumed technically easy, difficult, very difficult were not statistically different between both groups (Table 4). No blood transfusion, uterine perforations, cervical lacerations, vessels injuries, injuries to viscera (cytotomy, enterotomy, ureteric injury) or need to laparotomy in either groups.

Postoperative pain scores was significantly lower in BER group than in NDVH group at all time periods (at 3h, 12h, 24h, $\mathrm{P}=0.002, \quad \mathrm{P}=0.0003, \mathrm{P}=0.0003$, respectively) and total inpatient need for postoperative analgesia (both narcotic and NSAID) were more in NDVH group $(\mathrm{P}<0.0001, \mathrm{P}<0.001$, respectively) (table 4).

The mean duration of hospital stay was significantly lower in BER group than NDVH group $(\mathrm{P}<0.0001)$ (Table 4). There were no early or late complications such as fever, endometritis, urinary tract infections, hematoma, pneumonia, thromboembolism, cardiopulmonary arrest in either group.

At 6 month follow up there was significant reduction from baseline in number of patients complaining of dysmenorrhea, pelvic pain, backache, high urinary frequency and dyspareunia in both groups. The number of women for whom symptoms had improved by 6 months did not differ between BER and NDVH groups (Table 5). 
On evaluating, the quality of life score at 6month postoperatively in comparison with the pretreatment status, in both groups namely BER and NDVH, the UFS - T S\% mean was significantly reduced and the $\quad$ HR-T S\% mean was significantly improved as presented in table (2), but the reduction in UFS - T $\mathrm{S} \%$ and the improvement in $\mathrm{HR}-\mathrm{T} \mathrm{S} \%$ were in favor of NDVH over BER as presented in table (3).

\section{$\underline{\text { Discussion }}$}

In the current study, all participants whom underwent $\mathrm{BER}$ for $\mathrm{HMB}$ induced by leiomyoma were cured from $\mathrm{HMB}$ at 6 months after surgery $(\mathrm{PBAC}<80$ ). A part from three women (15\%) underwent NDVH at 12 months all women remained cured from HMB up to 24 month. More ever shorter operative time, less blood loss, lower postoperative pain, lower amount of analgesia and shorter hospital stays were recorded in women underwent BER than whom underwent NDVH. While the hemoglobin levels, the SSS and HRQOL scores were improved in both groups at 6 months postoperative, despite that, the mean difference in UFS-TS $\%$ reduction and $\mathrm{HR}-\mathrm{TS} \%$ improvement were significant in favor of NDVH over BER.

To the best of my knowledge this is the first trial comparing BER with NDVH. A comparable outcomes were reported by many authors, but on different trials design and different studied items.

Several authors ${ }^{(4,6,10,11,12,13,14)}$ have investigated the efficacy of MREA in women with HMB in comparing with hysterectomy or other methods of EA reporting varying success rates ranging from $83 \%$ to $91 \%$ while trials comparing the efficacies of EA and NDVH in HMB in association with leiomyomas were few ${ }^{(15,16)}$.

Dickersin et al. ${ }^{(10)}$ conducted multicenter trial comparing (118) hysterectomy (by different routes) to (110) EA (including MREA and NREA) among women with normal sized uterus without organic pathology assessing the women's main symptoms resolution (which was mainly HMB). They found that EA had $84.9 \%$ efficacy in controlling women's main symptom, compared to $94.4 \%$ for hysterectomy. They also, reported $40 \%(28 / 70)$ adverse minor and major events in NDVH subgroup while the adverse event was 13\% (7/58) in MREA subgroup.

Crosignani et al. ${ }^{(16)}$ compared (41) hysteroscopic endometrial resection (HER) versus (44) NDVH in women with mobile uteri $\leq 12$ weeks pregnancy size without any leiomyomas except intracavitery $\leq 3$ $\mathrm{cm}$ and they confirmed the effectiveness of HER in treatment of menorrhagia but the health related quality of life and satisfaction rate were significantly slightly higher at 2 year follow up in women whom NDVH were done. Similar results were reported by Tappero and Heinonen ${ }^{(12)}$ when compared HER to laparoscopic assisted vaginal hysterectomy (LAVH) and Pinion et al. ${ }^{(14)}$, when comparing hysterectomy to endometrial lazer ablation and HER and Zupie et al. ${ }^{(13)}$, when compared HER with supracervical hysterectomy. A cohrane review(4) investigated endometrial resection / ablation techniques in comparison to Hysterectomy by different routes for treatment of abnormal uterine bleeding in premenoposual women and concluded that both MREA and NREA should be considered alternative to hysterectomy as both procedures are effective in controlling women's symptoms and both associated with high women's satisfaction rates despite that hysterectomy is associated with longer operative times, a longer recovery period, higher postoperative complications and higher costs in relation to EA, while hysterectomy offers permanent cure for HMB.

Trials evaluating the efficacy of EA on HMB induced by leiomyoma were few. Soysal et al. ${ }^{(9)}$ compared roller ball endometrial ablation (REA) with thermal balloon ablation (TBA) in women with $\mathrm{HMB}$ induced by leiomyoma up to $5 \mathrm{~cm}$ and found that both techniques were effective in controlling HMB (the reduction in PBAC were from 385 to 40 in REA) and significant improvement of hemoglobin levels after one year follow up. Jain et al. ${ }^{(15)}$ compared TBA with NDVH in women with HMB induced by leiomyoma and found that TBA was highly efficacious in controlling HMB and other leiomyoma related symptoms as well as improvement in postoperative hemoglobin and quality of life but the improvement in UFS - T S\% and HR-T $\mathrm{S} \%$ were in favor of NDVH over TBA.

The results of the current study were similar to that of Soysal et al. and Jain et al. ${ }^{(9,15)}$ but in this trial a new technique to destruct the endometrium namely bipolar endometrial resection (BER) was used.

The present trial assessed other leiomyomata induced symptoms after BER and NDVH, improvements of symptoms were found to reach significant level in both groups, including dysmenorrhea, backache, pelvic pain, dyspareunia. This results like that of $\mathbf{J a i n}$ et al. ${ }^{(15)}$ and this could be explained by decrease of prostaglandins synthesis by removed endometrium.

The adverse events including both early and late postoperative as well as minor and major intraoperative were not noted in both groups. This may be secondary to safety of bipolar hysteroscopy and careful assessment of all participants preoperatively.

The limitations of the current trial include the small 
sample size, shorter period of follow up and lack of uterine size reduction assessment in group of women under went BER.

\section{Conclusion:}

The present study compares BER with NDVH in treatment of HMB induced by leiomyoma and other leiomyoma associated symptoms and found that BER is efficacious, minimally invasive, cost effective alternative to the NDVH in premenoposual women with $\mathrm{HMB}$ induced by leiomyomas. BER could be offered as first line treatment for women with HMB even with leiomyomata $\leq 3 \mathrm{~cm}$.

Conflict of interest : None.

Financial discolosure : None.

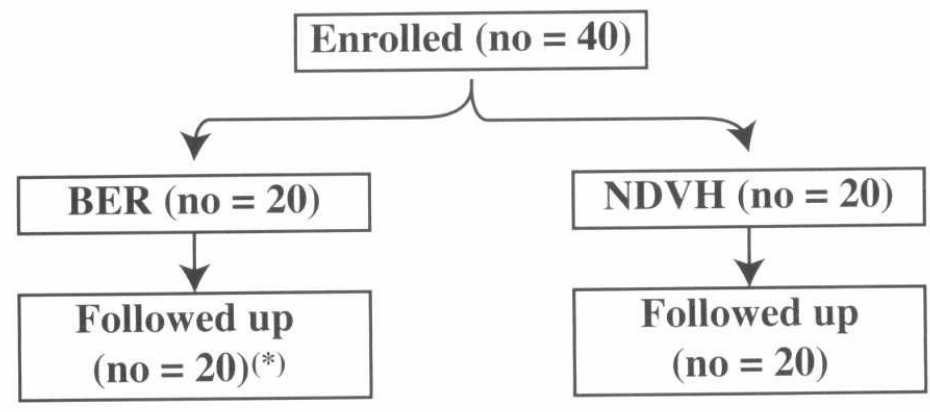

Figure (1)

follow chart of women underwent BER and NDVH.

Abbreviation: BER: Bipolar endometrial resection, NDVH: Nondescent vaginal hysterectomy.

* Three women underwent NDVH 12 months after BER

Table 1: Baseline demographic and clinical criteria of women underwent BER and NDVH.

\begin{tabular}{|l|c|c|c|}
\hline \multicolumn{1}{|c|}{ Variable(a) } & BER (no= 20) & NDVH (no= 20) & P value \\
\hline - Age (year) & $43.23 \pm 3.31(40-48)$ & $44.85 \pm 2.95(40-50)$ & 0.11 \\
\hline - Parity & $2.91 \pm 1.72(2-6)$ & $3.35 \pm 1.30(2-7)$ & 0.36 \\
\hline - Body mass index (kg/m2) & $27.53 \pm 4.61(22.30-35.50)$ & $28.5 \pm 3.95(21.32-36.50)$ & 0.47 \\
\hline - Duration of menstrual flow (day) & $8.9 \pm 5.1(4-18)$ & $9.2 \pm 4.9(5-19)$ & 0.85 \\
\hline - PBAC score & $634.3 \pm 270.2(230-950)$ & $652.2 \pm 210.2(280-940)$ & 0.81 \\
\hline - Duration of HMB (year) & $1.93 \pm 1.51(0.35-5.2)$ & $1.83 \pm 1.25(0.6-4.8)$ & 0.82 \\
\hline - Symptom severity score & $28.35 \pm 3.62(24-36)$ & $27.83 \pm 2.90(22-35)$ & 0.61 \\
\hline - USF-T S(\%) & $61.52 \pm 11.46(46.52-11.62)$ & $62.71 \pm 7.81(45.87-76.20)$ & 0.50 \\
\hline - HR - QOL score. & $108.80 \pm 6.36(81-113)$ & $107.82 \pm 6.37(85-114)$ & 0.62 \\
\hline - HR -T S\% & $34.28 \pm 6.20(25.70-55.20)$ & $31.85 \pm 5.54(25.72-52.22)$ & 0.19 \\
\hline - Hemoglobin gm/dl & $9.6 \pm 1.5(8.3-10.3)$ & $9.4 \pm 1.4(8.2-10.3)$ & 0.66 \\
\hline - Uterocervical length (cm) & $9.90 \pm 1.2(8-12)$ & $9.50 \pm 1.3(8-12)$ & 0.31 \\
\hline
\end{tabular}

Abbreviations: PBAC : Pictorial blood loss assessment chart, USF-TS\% : Uterine fibroid symptom transformed score, HR-TS\%: Health related transformed score. HR-QOL: Health related - Quality of life. BER: Bipolar endometrial resection, NDVH: Nondescent vaginal hysterectomy.

(a) $=$ values are expressed as mean \pm standard deviation (range).

$\mathbf{P}<\mathbf{0 . 0 5}$ : Statistically significant. 
Table 2: Quality of life outcome in BER and NDVH groups(a) ( $t$ test of paired sample)

\begin{tabular}{|l|c|c|c|c|c|c|}
\hline \multirow{2}{*}{} & \multicolumn{3}{|c|}{ USF-T S\% } & \multicolumn{3}{c|}{ HR - T S\% } \\
\cline { 2 - 7 } & Pretreatment & At 6 months & $\begin{array}{c}\text { P } \\
\text { value }\end{array}$ & Pretreatment & At 6 months & $\begin{array}{c}\text { P } \\
\text { value }\end{array}$ \\
\hline BER(no=20) & $61.52 \pm 11.46$ & $9.98 \pm 1.22$ & $<0.0001$ & $34.28 \pm 6.20$ & $90.32 \pm 9.32$ & $<0.0001$ \\
\hline NDVH(no=20) & $62.71 \pm 7.81$ & $1.82 \pm 0.91$ & $<0.0001$ & $31.85 \pm 5.54$ & $95.23 \pm 3.63$ & $<0.0001$ \\
\hline
\end{tabular}

Abbreviations: USF-TS\%: Uterine fibroid symptom transformed score, HR-TS\%: Health related transformed score. BER: Bipolar endometrial resection, NDVH: Nondescent vaginal hysterectomy.

(a) $=$ values are expressed as mean \pm standard deviation.

$\mathbf{P}<\mathbf{0 . 0 5}$ : Statistically significant.

Table 3: Comparison of quality of life outcome and hemoglobin changes in BER and NDVH groups(a) ( $t$ test of independent sample).

\begin{tabular}{|c|c|c|c|c|c|}
\hline & $\operatorname{BER}(\mathrm{no}=20)$ & $\operatorname{NDVH}(n o=20)$ & $\begin{array}{l}\Delta \text { value } \\
\text { change }\end{array}$ & $95 \% \mathrm{CI}$ & Pvalue \\
\hline$\Delta$ Mean reduction in USF-TS $\%$. & $\neg 52.54 \pm 8.54$ & $60.89 \pm 7.42$ & 8.35 & $\begin{array}{l}3.22 \\
\text { to } \\
13.47\end{array}$ & 0.002 \\
\hline $\begin{array}{l}\Delta \text { Mean improvement in } \mathrm{HR}-\mathrm{T} \\
\mathrm{S} \%\end{array}$ & $56.04 \pm 9.22$ & $63.38 \pm 8.84$ & 7.34 & $\begin{array}{c}1.55 \\
\text { to } \\
13.12\end{array}$ & 0.014 \\
\hline$\Delta$ Mean increase in $\mathrm{HB} \mathrm{g} / \mathrm{dl}$ & $2.60 \pm 0.9$ & $2.54 \pm 1.1$ & 0.06 & $\begin{array}{c}-0.70 \\
\text { to } \\
0.58\end{array}$ & 0.85 \\
\hline
\end{tabular}

Abbreviation: USF-T S\%: Uterine fibroid symptom transformed score, HR-T S\%: Health related transformed score, BER: Bipolar endometrial resection, NDVH: Nondescent vaginal, HB: Hemoglobin.

(a) $=$ values are expressed as mean \pm standard deviation.

$\mathbf{P}<\mathbf{0 . 0 5}$ : statistically significant.

Table 4: Preioperative outcomes in BER and NDVH groups.

\begin{tabular}{|l|c|c|c|}
\hline \multicolumn{1}{|c|}{ Variable $^{(\mathbf{a})}$} & BER (no= 20) & NBVH (no= 20) & P value \\
\hline - Operating time (mint) & $30.60 \pm 8.50$ & $90.50 \pm 20.80$ & $<0.0001$ \\
\hline - Blood loss (ml) & $50 \pm 10$ & $350 \pm 185$ & $<0.0001$ \\
\hline - Blood transfusion & 0 & 0 & \\
\hline -Intraoperative complication & 0 & 0 & \\
\hline - Technical difficulity : & & & \\
* Easy & $15(25 \%)$ & $5(25 \%)$ & $>0.99$ \\
* Difficult & $5(50 \%)$ & $10(50 \%)$ & $>0.99$ \\
*Very difficult & $5(25 \%)$ & $5(25 \%)$ & $>0.99$ \\
\hline
\end{tabular}




\begin{tabular}{|c|c|c|c|}
\hline $\begin{array}{l}\text { - Postoperative pain }(\mathrm{VAS}) \\
(0=\text { non, } 100=\text { worst }) \\
\quad * \text { at } 3 \mathrm{~h}\end{array}$ & $3.5 \pm 0.9$ & $4.6 \pm 1.2$ & 0.002 \\
\hline$*$ at $12 \mathrm{~h}$ & $2.5 \pm 0.8$ & $3.8 \pm 1.2$ & 0.0003 \\
\hline$*$ at $24 \mathrm{~h}$ & $0.9 \pm 0.8$ & $2.1 \pm 1.1$ & 0.0003 \\
\hline $\begin{array}{l}\text { - Amount of analgesia: } \\
* \text { total Narcotic dose (mg) } \\
\text { *Total parentral NSAID (di- } \\
\text { clofenac Sodium) (mg) }\end{array}$ & $\begin{array}{c}9.2 \pm 4.1 \\
75(6.2)\end{array}$ & $\begin{array}{c}19.4 \pm 9.6 \\
112.5 \pm 6.3\end{array}$ & $\begin{array}{l}<0.0001 \\
<0.0001\end{array}$ \\
\hline * Hospital stay (h) & $21(6.2)$ & $38(8.2)$ & $<0.0001$ \\
\hline
\end{tabular}

Abbreviation: BER: Bipolar endometrial resection, NDVH: Nondescent vaginal hysterectomy, VAS: Visual analogue scale score, NSAID: Non steroidal anti-inflammatory drug.

(a) $=$ values are expressed as mean \pm standard deviation.

$\mathbf{P}<\mathbf{0 . 0 5}$ : statistically significant.

Table 5: Number of womens with resolution of symptoms after 6 months in BER and NDVH groups ${ }^{(1)}$.

\begin{tabular}{|c|c|c|c|}
\hline Symptoms & $\operatorname{BER}($ no $=20)$ & $\operatorname{NBVH}($ no $=20)$ & P value ${ }^{(2)}$ \\
\hline $\begin{array}{l}\text { - Dysmenorrhea } \\
\text { P value }^{(3)}\end{array}$ & $\begin{array}{l}14 / 14(100 \%) \\
\quad<0.0001\end{array}$ & $\begin{array}{l}17 / 17(100 \%) \\
\quad<0.0001\end{array}$ & $>0.99$ \\
\hline $\begin{array}{l}\text { - Pelvic pain } \\
\text { P value } \\
\text { (3) }\end{array}$ & $\begin{array}{c}12 / 14(85 \%) \\
<0.001\end{array}$ & $\begin{array}{c}13 / 13(100 \%) \\
<0.001\end{array}$ & 0.75 \\
\hline $\begin{array}{l}\text { - Backache } \\
\quad \text { P value } \\
\end{array}$ & $\begin{array}{c}11 / 16(68 \%) \\
0.002\end{array}$ & $\begin{array}{c}9 / 17(52 \%) \\
0.004\end{array}$ & 0.68 \\
\hline $\begin{array}{l}\text { Increased urinary frequency } \\
\quad \mathrm{P} \text { value }{ }^{(3)}\end{array}$ & $\begin{array}{c}3 / 5(75 \%) \\
0.52\end{array}$ & $\begin{array}{l}6 / 6(100 \%) \\
0.62\end{array}$ & 0.58 \\
\hline $\begin{array}{c}\text { - Dyspareunia } \\
\text { P value }{ }^{(3)}\end{array}$ & $\begin{array}{c}3 / 3(100 \%) \\
0.82\end{array}$ & $\begin{array}{c}8 / 8(100 \%) \\
0.008\end{array}$ & $>0.99$ \\
\hline
\end{tabular}

Abbreviations: BER: Bipolar endometrial resection, NDVH: Nondescent vaginal hysterectomy.

1. Values are expressed as number of women with resolved symptoms at 6 month / number of women who had symptoms before treatment (percentage)

2. Comparison between BER and NDVH groups.

3. Comparison in the same group with the baseline. 


\section{References}

1. Middleton LJ, Champaneria R, Daniels JP, Bhattacharya S, Cooper KG, Hilkin NH, et al. Hysterectomy, endometrial destruction, levonogrestrel releasing intrauterine system (Mirena) for heavy menstrual bleeding: systematic review and meta - analysis of data from individual patients. BMJ 2010; 34 : c3929.

2. Eisinger HS, Meldrum S, Fiscella K, le Roux HD and Guzick DS. Low-dose mifepristone for uterine leiomyomata. Obstet Gynecol 2003; 101 (2): 243 - 50.

3. Cross K and Morton CC. Genetics and the development of fibroids. Clin Obstet Gynecol $2001 ; 44: 335-49$.

4. Fergusson RJ, Lethaby A, Shepperd $\mathrm{S}$ and Farquhar C. Endometrial resection and ablation versus hysterectomy for heavy menstrual bleeding. Cochrane Database Syst Rev 2013 : 11. CD000329.

5. Sharp HT.Assessment of new technologies in he treatment of idiopathic menorrhagia and uterine leiomyomata. Obstet Gynecol 2006; 108 (4): 990 - 1003.

6. Laberge P, Leyland N, Murji A, Fortin C, Mortyn $\mathrm{P}$ and Vilos G. Endometerial ablation in the management of abnormal uterine bleeding. J obstet Gynecol Can. 2015, 37 (4): 362 - 376.

7. Spies JB, Coyne K, Guaou NG, Boyle D, Skyrnarz - Murphy K and Gonzalves SM. The UFS-QOL, a new disease - specific symptom and health related quality of life questionnaire for leiomyomata. Obstetrics, Gynecology 2002; 99, No. 2, 290 - 300.

8. Harding G, Coyne KS, Thompson CL and Spies JB. The responsiveness of the uterine fibroidsymptom and health - related quality of life questionnaire (UFS -QOL). Health Qual Life Outcomes 2008; 6 : 99.

9. Soysal ME, Soysal SK and Vicdan K. Thermal balloon ablation in myoma - induced menorrhagia under local anesthesia. Gynecol Obstet Invest $2001 ; 51$ (2) : $128-33$.

10. Dickersin K, Munro MG, Clark M, Langenberg P, Scherer R, Frick K, et al. Hysterectomy compared with endometrial ablation for dysfunctional uterine bleeding, a randomized controlled trial. Obstet Gynecol 2007, 110 (6) : $1279-89$.

11. Pellicano M, Guidu M, Acunzo G, Girillo D, Bisulco $\mathrm{G}$ and Nappi C. Hysteroscopic transcervical endometrial resection versus thermal destruction for menorrhagia : A prospective randomized trial on satisfaction rate. Am J Obstet Gynecol 2002; 187 (3) : $545-550$.

12. Tapper AM and Heinonen PK. Comparison of hysteroscopic endometrial resection and laparoscopic assisted vaginal hysterectomy for treatment of menorrhagia Acta Obstet Gynecol Scand 1998: $77: 78-82$.

13. Zupi E, Zullo F, Marconi D, Sbrarica M, Pellicano M, Solima E and Sorrenti G. Hysteroscopic endometrial resection versus laproscapic supracervical hysterectomy for menorrhegia. A prospective randomized trial. Am J Obstet Gynecol $2003 ; 188$ (1): $7-12$.

14. Pinion SB, Parkin DE, Abramovicin DR, Naji A, Alexander DA, Russel IT and Kitchener HC. Randomized trial hysterectomy, endometrial laser ablation and transcervical endometrial resection for dysfunctional uterine bleeding. BMJ 1994; 309 : $979-983$.

15. Jain P, Rajaram S, Gupta B, Goel N and Srivastava H. Randomized controlled trial of thermal balloon ablation versus vaginal hysterectomy for leiomyoma induced heavy menstrual bleeding. Int $\mathrm{J}$ Gynecol Obstet (2016). http://dx.doi.org/10.1016/j. ij90.2016.04.020.

16. Crosignani PG, Vercellini P, Apolone G, Giorgi OD, Cortesi I and Meschia M. Endometrial resection versus vaginal hysterectomy for menorrhagia : long-term clinical and quality - of - life outcomes. Am J Obstet Gynecol 1997, 177 (1): 95 - 101.

\section{Abbreviations:}

$\begin{array}{ll}\text { EA } & \text { : Endometrial ablation. } \\ \text { BER } & \text { : Bipolar endometrial resection. } \\ \text { NDVH } & \text { : Nondescent vaginal hysterectomy. } \\ \text { REA } & \text { : Resectoscopic endometrial ablation. } \\ \text { NREA } & \text { : Non resectoscopic endometrial abla- } \\ \text { tion. } & \end{array}$

MREA : Monopolar resectoscopic endometrial ablation.

HB : Hemoglobin

PBAC : Pictorial blood loss assessment chart.

VAS : Visual analogue scale score.

USF-QOL : Uterine fibroid symptom quality of life questionnaire.

SSS : Symptoms severity score.

HR-QOL : Health related quality of life score.

HR-TS : Health related transformed score.

UFS-TS : Uterine fibroid symptom transformed score. 